\title{
The Social Media and Technology Addiction and Its Associated Factors among University Students in Lebanon Using the Media and Technology Usage and Attitudes Scale (MTUAS)
}

\author{
Hala Sabbah1, Rêve Berbari², Rania Khamis³, Dalia Zorkot², Sanaa Sabbah',4, Nabil Droubi5, \\ Ibtissam Sabbah ${ }^{2 *}$ (B)
}

\author{
${ }^{1}$ Faculty of Economic Sciences and Business Administration, Lebanese University, Nabatieh, Lebanon \\ ${ }^{2}$ Faculty of Public Health, Lebanese University, Saida, Lebanon \\ ${ }^{3}$ Institute of Social Science, Lebanese University, Saida, Lebanon \\ ${ }^{4}$ Doctoral School of Literature, Humanities \& Social Sciences, Lebanese University, Beirut, Lebanon \\ ${ }^{5} \mathrm{MD}$, Saida, Lebanon \\ Email: hsabbah@ul.edu.lb,rricha@ndu.edu.lb, Rania_kh2@hotmail.com,Daliazorkot1234@gmail.com, \\ Sabbahsanaa@gmail.com, nsdroubi@inco.com.lb, ^ibtissam.sabbah@ul.edu.lb, *ibtissam.sabbah@gmail.com
}

\begin{abstract}
How to cite this paper: Sabbah, H., Berbari, R., Khamis, R., Zorkot, D., Sabbah, S., Droubi, N. and Sabbah, I. (2019) The Social Media and Technology Addiction and Its Associated Factors among University Students in Lebanon Using the Media and Technology Usage and Attitudes Scale (MTUAS). Journal of Computer and Communications, 7, 88-106. https://doi.org/10.4236/jcc.2019.711007
\end{abstract}

Received: October 21, 2019

Accepted: November 24, 2019

Published: November 27, 2019

Copyright $\odot 2019$ by author(s) and Scientific Research Publishing Inc. This work is licensed under the Creative Commons Attribution International License (CC BY 4.0).

http://creativecommons.org/licenses/by/4.0/ c) (i) Open Access

\begin{abstract}
The contemporary developments of Information and Communication Technologies usage have fueled a popular concern. The young people are experiencing technology addiction behavior due to excessive media and technology usage. A valid instrument is required to detect individuals at high risk of social media and technology addiction. Objective: The objectives of this study are to assess prevalence of the technology addiction using the Media and Technology Usage and Attitudes Scale (MTUAS) and to investigate the impacts of online social networking on health and academic performance of young university students in Lebanon. Methods: During the academic year 2017-2018, a cross-sectional study which enrolled 705 young university students was conducted. Data was collected using MTUAS questionnaire. The translation and cultural adaptation of the MTUAS followed a standardized protocol. The psychometric properties were then evaluated. We used multivariate regression analyses to determine which characteristics were associated with the technology addiction among students. Results: 705 filled out the questionnaire aged 17 to 35 years $($ mean $=20.42$; $\mathrm{SD}=2.41), 74 \%$ of whom were females. The internal consistency was high for all subscales and ranged from $0.54-0.87$. The MTUAS yielded statistically significant scores for subgroups (known group validity). Males' students had a higher risk of addiction to social media and technology than females. The use of media was viewed com-
\end{abstract}


mon among the smokers $(\mathrm{OR}=1.76 ; 95 \% \mathrm{CI}=1.10-2.82, \mathrm{p}=0.02)$ and drinkers of alcohol $(\mathrm{OR}=1.80 ; 95 \% \mathrm{CI}=1.04-3.11, \mathrm{p}=0.04)$. Students that used e-mailing, smartphone, and TV viewing had a high academic performance level. Females and public university students had negative attitudes toward technology. In conclusion: The technology becomes a big problem on the universities students' users that has an impact on their life and affects their academic performance. The MTUAS Arabic version has been evaluated as a valid and reliable instrument.

\section{Keywords}

Media and Technology Usage and Attitudes Scale (MTUAS), Technology Addiction Behavior, Young University Students, Academic Performance

\section{Introduction}

The use of Information and Communication Technologies (ICT) such as the internet and mobile phones has increased dramatically and been accessible to thousands of millions of people worldwide. The developments in information technologies have led to the production of such tools as mobile phone, desktop computer, laptop computer, smart TV, and tablet, and to their marketing with a low price [1]. Social media are a series of websites and applications designed to allow people to share content quickly, efficiently and in real-time [2]. Social media contribute to the transformation of users from passive listeners to active content producers. It makes it easier to stay connected and to produce content by providing applications for different mobile devices and operating systems [3]. The ability to share photos, opinions, events, etc. in real-time has transformed the way we do life, and it is also transforming the way we do business [2].

New technologies have great benefits for students regarding their education, socialization, communication, and their academic performance. Many universities around the world have transformed their courses. Distance education has become much more popular [4]. Students and instructors could easily interact with each other through social networks [4]. The social media sites like Facebook, Twitter, Google+, and Skype capture the attention of students to study and affecting their academic Grade points positively [5] [6]. They also have negative impact on students' studying and habits [7].

As technology empowers humans to achieve many unthinkable things, it is also seen as the cause of several problems in society. The contemporary developments of ICT usage have fueled a popular concern that young internet users are experiencing Internet addiction due to excessive Internet use [4] [8]. Some people become obsessed with the Internet, are unable to control their use of it, and may put their work and relationships in jeopardy [9]. The addictions such as gambling, doing sports excessively, spending time with digital tools overmuch, etc. are classified as "behavioral addiction" [1]. Popular media often cover news 
stories discussing the narcissism associated with heavy use of social networks and describe an addiction that young people live with [10]. Most of the features of addictions, such as salience, compulsive use (loss of control), the alleviation of distress, tolerance and withdrawal, mood modification, and the continuation despite negative consequences are growing in Internet addiction too [4].

The transition from normal to problematic social media use is seen as an important mechanism to alleviate stress, loneliness or depression for the individual, so they become more active with more social media [3]. Social media and technology addiction were associated with self-reported negative effects on productivity, both in the workplace and in participants' daily lives [11]. Several independent risk factors emerged including excessive use of smartphone, personality type A, depression, anxiety, and a possible lack of family social support (indicated by not calling family members) [12]. Many people who feel lonely try to open instant conversations and to extend their circle of friends through social networks [13].

Along with the gradual spread of the Internet, the measurement of the usage frequency of Internet and affiliated technologies has started to gain importance [8] [14]. Regarding recent youth smartphone addiction in college students figures collected in Lebanon, almost $35.9 \%$ felt tired during daytime due to latenight smartphone use, $38.1 \%$ acknowledged decreased sleep quality, and $35.8 \%$ slept less than four hours due to smartphone use more than once [12].

In the past decade, various scales have been developed for measuring engagement with social network sites, but validity concerns have recently been raised about some of them [15]. The Media and Technology Usage and Attitudes Scale (MTUAS), which had been developed by Rosen et al. (2013), was adapted to Turkish [14], Portuguese [8]. Boumosleh \& Jaalouk [12] investigated whether anxiety and depression independently contributed to smartphone addiction using the 26-item Smartphone Addiction Inventory (SPAI) Scale. Their sample was 668 random Lebanese undergraduate students at one private university, recruited from the pool of "Natural Sciences". Samaha et al. [16] assessed the psychometric properties of the Internet Addiction Test (IAT) among 256 medical students enrolled from a private university in Lebanon.

In Lebanon, there is a need for more information about young media and technology abuse and about the most appropriate programs for treating them. There is a scarcity of research on media and technology addiction, using a valid instrument, in both public and private university setting in Lebanon. Our research questions are: what are the levels of students' media and technology addiction? Are there any significant differences in health and academic performance of media and technology-addicted and not-addicted students?

The main objectives of this study are: 1) to assess prevalence of the media and technology usage as well as attitudes toward technology using the Media and Technology Usage and Attitudes Scale among young university students; and 2) to assess health problems related to social media and technology usage across 
these groups; and 3) to investigate the impacts of online social networking on students' academic performance in university settings.

\section{Materials and Methods}

\subsection{Study Design}

From April to September 2018, a cross-sectional survey was conducted among a population of young university students in South and Mount Lebanon. The faculties that consented to participate were enrolled in our study. After obtaining approval from the Directors of the faculties, data were collected using self-administered questionnaires. The classes were chosen randomly in the faculties whose administrators consented to participate. The students were approached after class and asked to participate in the study. They were informed that the survey was voluntary and confidential. The consent form was presented at the beginning of the questionnaire. A completed questionnaire was considered evidence of the consent to the study. The investigators, in number of four, were present during several times of the day to ensure the filling out of the questionnaires by the students. The questionnaire took $10-15$ minutes to be completed.

The target population in the faculties during the academic year 2017-2018 was 2000. Seven faculties participated in our study, including two in Mount Lebanon, one private and one public, and five in southern Lebanon, three of which were public and two private. The sample size was determined by adopting the following statistical formula for minimum sample size calculation. With a population of 2000 , a margin of error is $3.64 \%$, a $95 \%$ confidence level, and the response distribution is $50 \%$, the required sample size is 700 students distributed to all the faculties concerned (http://www.raosoft.com/samplesize.html). So the sample was between 100 and 150 students for each faculty.

\subsection{Questionnaire}

The study questionnaire had three sections. The first section developed by the authors of this study contained questions on demographic characteristics of the study participants (gender, age, residency area, living with parents (yes/no), specialization, and current occupation. Health behaviors (smoking, alcohol consumption, and physical activities) and medical conditions were also self-reported by the students.

In the second section of the questionnaire the academic performance was collected: data obtained about the Grade Point Average (GPA) of the students for fall 2017-2018.

Finally, to measure media and technology usage, the scale used in this study was Media and Technology Usage and Attitudes Scale (MTUAS). It was developed in English by Rosen et al. [17] for determining media and technology usage and attitudes, and may be used without getting any permission and without paying any fee [8] [14]. It assess self-reported frequency of media and technolo- 
gy use as well as attitudes toward technology use, rather than relying on inaccurate self-reports of time spent using a variety of technologies [17].

The MTUAS included 60 items. It is a self-report instrument that assesses information technology and social media usage (44 items) as well as attitudes of adults toward technology (16 items).The first 40 items, regarding technology and media usage include the following subscales: Smartphone usage (nine items); general social media usage (nine items); and Internet searching, e-mailing, and media sharing (four items). Text messaging (SMS) and video gaming sub-factors for the scale consist of three items; online friendships, social media friendships, phone calling, and television (TV) viewing sub-factors each consist of two items. The items 41 to 44 describe the use of social media, especially Facebook. The last four sub-factors for determining attitudes related to media and technology usage are positive attitudes toward technology (six items), anxiety of being without technology/technology dependency(three items), negative attitudes towards technology (three items), and multitasking preferences (four items, one reverse scored).

The first nine factors of the scale, consisting of 40 items (smartphone usage, general social media usage, Internet searching, e-mailing, media sharing, text messaging (SMS), video gaming, phone calling, and television viewing) were made into a 10-point Likert structure (never-always). The 10th and 11th sub-factors (online friendships and social media friendships) that covered four items of the scale were applied in a 9-point Likert structure (from 0, 1 - 5, 51 - 100, 101 - 175, 176 - 250, 251 - 375, 376 - 500, 501 - 750 to 751 friendships or more). The 12th through 15th sub-factors of the scale (positive attitudes towards technology, anxiety of being without technology/technology dependency, negative attitudes towards technology, and multitasking preferences), which determined their opinions related to attitude, were applied using a 5-point Likert structure (strongly agree, agree, neither agree nor disagree, disagree, strongly disagree).

The authors stated that a total score for the full-scale MTUAS can be derived; a higher score on the full-scale MTUAS indicated increased social media use or an increased number of social media friends relative to other participants [17]. Addicted to technology group is defined as total score equal or greater than 5 (score $\geq 5$ ) for all domains of the usage subscales and for the full-scale MTUAS scores.

\subsection{Cultural Adaptation of the MTUAS in Arabic}

Regarding the translation process, in a first step the scale was translated to Arabic. Next, a back translation was made by a different translator and compared with original version. Finally, the discrepancies were corrected. Finally, a pretest was conducted on a group (20 subjects) of lay native Arabic speakers. For each item, the group was asked to explain how it was understood. The participants indicated no difficulties in answering the items. According to these results, some minor changes were made. 


\subsection{Statistical Analysis}

Analyses were conducted using frequencies, means, and standard deviations (SDs) to describe the characteristics of the participants. Mean score and standard deviation (SD), 95\% CI for mean, median score, and interquartile range separate MTUAS subscales and for the full-scale MTUAS scores. Since the data were normally distributed, differences between groups and the 15 subscales of the MTUAS were tested with chi-square statistics or one way analysis of variance (ANOVA) when appropriate. Technology addiction scores were treated as a bivariate variable with a score of " 5 " or more indicating a technology addiction disorder.

The feasibility of the MTUAS was assessed by determining the proportion of missing values per item [18] [19]. The internal consistency of each subscale of the scale was determined using Cronbach's alpha reliability coefficient.

The construct validity of the MTUAS was assessed in terms of known groups' validity (both convergent and discriminant validity can be tested). We hypothesized that the MTUAS subscales and total scores differ among youth students' subgroups. This validity of known groups makes it possible to evaluate the proportions of addiction to technology in subgroups at once.

Multivariate analysis was performed by stepwise logistic regression of the dichotomized full-scale MTUAS scores data(cutoff score $<5$ versus $\geq 5$ ) taking in consideration the gender, age, university type, living with parents, working status, GPA, alcohol and tobacco use, physical activity, neck pain, and headache to determine which characteristics were associated to the full-scale MTUAS scores among young students. A variable is added to the model if the significance level is less than or equal 0.05 .

All statistical analyses were performed by using SPSS version 22.0 (SPSS, Chicago, IL). All tests of significance were two-tailed. p-value $\leq 0.05$ considered to be the critical level of significance.

\section{Results}

\subsection{Respondent Characteristics}

A summary of the characteristics of the respondents stratified by gender is presented in Table 1 . The faculties that participated in the study were seven in the three areas: South, Nabatieh, and Mount Lebanon. Seven hundred and five young university students participated in this study, of which $74 \%$ were female, ranging in age from 17 to 35 (mean $=20.42$; median $=20$ years; $\mathrm{SD}=2.41$ ). $34.5 \%$ living in urban areas. Approximately two third of participants $(61.8 \%)$ belong to the age range of 20 to 29 years, while more than third of them $(36.5 \%)$ belong to the age range of 17 to 19 years. More than half of respondents live in rural areas (65.5\%). Regarding educational level, five levels were considered: approximately one third $(31.3 \%)$ of participants were in the first year, $39 \%$ in the second, $24.8 \%$ in the third, $4 \%$ in the fourth and $0.9 \%$ and in the fifth grade. Student-reported areas of study were as follows: humanities and education 
Table 1. Characteristics and academic performance of the respondents.

\begin{tabular}{|c|c|}
\hline Variables & Frequency (\%) \\
\hline Total (\%) & $705(100)$ \\
\hline \multicolumn{2}{|l|}{ University } \\
\hline Private & $205(29.1)$ \\
\hline Public & $500(70.9)$ \\
\hline \multicolumn{2}{|l|}{ Residency area } \\
\hline Urban & $243(34.5)$ \\
\hline Rural & $461(65.5)$ \\
\hline \multicolumn{2}{|l|}{ Age } \\
\hline $17-19$ & $275(36.5)$ \\
\hline $20-29$ & $436(61.8)$ \\
\hline 30 and higher & $12(1.7)$ \\
\hline \multicolumn{2}{|c|}{ living with parents } \\
\hline Yes & $632(89.6)$ \\
\hline No & $73(10.4)$ \\
\hline \multicolumn{2}{|l|}{ Working } \\
\hline Yes & $192(27.2)$ \\
\hline No & $513(72.8)$ \\
\hline \multicolumn{2}{|l|}{ GPA $(n=642)$} \\
\hline$<1.99$ & $21(3.3)$ \\
\hline $2-2.99$ & $300(46.7)$ \\
\hline$\geq 3$ & $321(50)$ \\
\hline \multicolumn{2}{|l|}{ Alcohol } \\
\hline Yes & $99(14)$ \\
\hline No & $606(86)$ \\
\hline \multicolumn{2}{|l|}{ Smoking } \\
\hline Yes & $142(20.1)$ \\
\hline No & $563(79.9)$ \\
\hline \multicolumn{2}{|l|}{ Physical activity } \\
\hline Yes & $438(62.1)$ \\
\hline No & 267 (37.9) \\
\hline \multicolumn{2}{|l|}{ Insomnia } \\
\hline Yes & $197(27.9)$ \\
\hline No & $508(72.1)$ \\
\hline \multicolumn{2}{|l|}{ Back pain } \\
\hline Yes & $251(35.6)$ \\
\hline No & $454(64.4)$ \\
\hline \multicolumn{2}{|l|}{ Neck pain } \\
\hline Yes & $198(28.1)$ \\
\hline No & 507 (71.9) \\
\hline \multicolumn{2}{|l|}{ Headache } \\
\hline Yes & $348(49.4)$ \\
\hline No & 357 (50.6) \\
\hline
\end{tabular}


(1.0\%), Engineering (6.0\%), Faculty of sciences (10.8\%), health sciences (19.7\%), Business Administration and computer sciences (16.2\%), Architecture and Design (18.9\%), social science (21.7\%), and Information sciences (5.8\%). The majority of students surveyed lived with their parents $(90.8 \%)$.

Regarding employment status, $27 \%$ of the students indicated that they were employed to be able to support themselves and their parents to finance their studies. Alcohol consumption was declared by $14 \%$ of respondents, $20.1 \%$ used tobacco, and $62.1 \%$ were physically active. Concerning health problems reported by the students, $35.6 \%$ of students had low back pain, $28 \%$ declared neck pain, $27.9 \%$ had insomnia, and $49.4 \%$ had a headache (Table 1 ).

\subsection{Academic Performance}

The mean grade point average (GPA) (4-point system) of the student participants was $69.75(\mathrm{SD}=13.01)$. The majority of students had an annual average between 50 - 69 (46.7\%) and 70 - 100 (50\%) (Table 1).

\subsection{Psychometric Characteristics of the MTUAS}

Table 2 displays the means, standard deviations, skewness scores and Cronbach's alpha coefficient of all 15 subscales.

Table 2. Description and homogeneity of the MTUAS subscales.

\begin{tabular}{|c|c|c|c|c|c|}
\hline \multirow{2}{*}{ Subscales } & \multirow{2}{*}{ Mean (SD) } & \multirow{2}{*}{ Skweness } & \multirow{2}{*}{ Cronbach alpha } & \multicolumn{2}{|c|}{$\%$ of addiction } \\
\hline & & & & Normal group $(<5)$ & Addiction group $(\geq 5)$ \\
\hline \multicolumn{6}{|c|}{ Usage subscales } \\
\hline E-mailing ${ }^{a}$ & $3.62(2.07)$ & 0.72 & 0.84 & 75.7 & 24.3 \\
\hline Text messaging ${ }^{\mathrm{a}}$ & $7.53(1.86)$ & -0.72 & 0.59 & 12.5 & 87.5 \\
\hline Phone calling ${ }^{\mathrm{a}}$ & $7.35(1.95)$ & -0.71 & 0.67 & 14.5 & 85.5 \\
\hline Smartphone usage $\mathrm{e}^{\mathrm{a}}$ & $5.75(1.63)$ & 0.22 & 0.79 & 35.3 & 64.7 \\
\hline TV viewing ${ }^{\mathrm{a}}$ & $5.01(2.13)$ & 0.19 & 0.65 & 56.5 & 43.5 \\
\hline Media sharing $^{\mathrm{a}}$ & $3.10(2.03)$ & 1.07 & 0.84 & 83.3 & 16.7 \\
\hline Internet searching ${ }^{\mathrm{a}}$ & $5.69(2.38)$ & 0.11 & 0.86 & 43.0 & 57.0 \\
\hline Video gaming $^{\mathrm{a}}$ & $3.50(2.63)$ & 0.92 & 0.86 & 75.5 & 24.5 \\
\hline General social media usage $\mathrm{e}^{\mathrm{a}}$ & $5.46(1.87)$ & -0.08 & 0.85 & 40.7 & 59.3 \\
\hline \multicolumn{6}{|c|}{ Use of social media subscales } \\
\hline Facebook friendships ${ }^{\mathrm{b}}$ & $6.10(2.19)$ & -0.65 & 0.87 & 32.0 & 68.0 \\
\hline Online friendships ${ }^{\mathrm{b}}$ & $2.31(1.50)$ & 1.80 & 0.65 & 94.9 & 5.1 \\
\hline \multicolumn{6}{|c|}{ Attitudes subscales } \\
\hline Positive attitudes ${ }^{c}$ & $3.96(0.59)$ & -0.53 & 0.77 & NA & NA \\
\hline Anxiety/dependence ${ }^{\mathrm{d}}$ & $3.57(0.90)$ & -0.45 & 0.81 & NA & NA \\
\hline Negative attitudes ${ }^{\mathrm{e}}$ & $3.54(0.82)$ & -0.27 & 0.68 & NA & NA \\
\hline Preference for task switching ${ }^{f}$ & $2.90(0.72)$ & -0.29 & 0.54 & NA & NA \\
\hline MTUAS full-scale ${ }^{g}$ & $4.75(0.92)$ & 0.15 & 0.91 & 60.1 & 39.9 \\
\hline
\end{tabular}

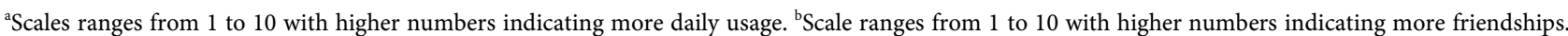
${ }^{\mathrm{c}}$ Scale ranges from 1 to 5 with higher scores indicating more positive attitudes toward technology. ${ }^{\mathrm{d}}$ Scale ranges from 1 to 5 with higher scores indicating more technological anxiety and dependence. ${ }^{~} S$ cale ranges from 1 to 5 with higher scores indicating more negative attitudes toward technology. ${ }^{\text {S }}$ cores range

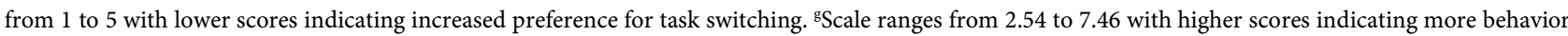
addiction toward technology. 
Only two subscales had suspect skewness scores: media sharing (1.07) and online friendships (1.80). Based on the mean scores across all participants, the social media use was relatively common among the students interviewed. The most commonly used technologies were text messaging (87.5\%), phone calling $(85.5 \%)$, Facebook friendships (68\%), Smartphone usage (64.7\%), and internet searching (57.0\%), and General social media usage (59.3\%). Facebook was the most popular online platform used by students where 689 participants (97.9\%) indicated that they had a Facebook page. Many (68\%) students had their own mobile phones and were able to access Facebook on their phones.

The Cronbach's alpha coefficients for the fifteen factors in total were found to be between 0.54 and 0.87 .

\subsection{Social Media and Technology Usage in Subgroups}

Compared with female students, male students had a higher risk of addiction to technology for all usage subscales except general social media usage subscale. In private universities, students spent more time on E-mailing, text messaging, phone calling, Internet or mobile phone usage, video gaming, and Facebook friendships. The students aged less than 30 years had a high risk of addiction to technology used E-mailing, TV viewing, media sharing, and Facebook friendships. However, residency location (urban or rural areas) had no significant influence on any subscale of the MTUAS. The students living in dormitories used E-mailing and Smartphone, shared media and Internet, and had Facebook friendships more than those living with their parents at home. The GPA level demonstrated significant differences with several subscales. Students that shared media had a low performance level, while others that used e-mailing, smartphone, and TV viewing (on a TV) had a high performance level. This may show us the positive effect of technology on the student's level of performance. The use of media and technology was viewed common among the smokers and drinkers of alcohol. Students who reported having an internet searching addiction suffered from insomnia $(\mathrm{p}$-value $=0.03)$ and backache $(\mathrm{p}=0.04)$. The users of media sharing declared backache, neck ache and headache more than the non-users (Table 3).

\subsection{Relationship between Sociodemographic Variables and Attitude towards Technology}

Table 4 showed that females had negative attitudes toward technology more than males $(\mathrm{p}$-value $=0.002)$. Public university students had a negative attitude towards technology and tended to change tasks more than students from private universities. Subsequently the others sociodemographic variables (e.g. age, residency location, living within their family or in dormitory, and work status) did not influence the students' attitude to technology. In addition, no relationships were established between lifestyle behaviors (use tobacco, alcohol, physical activities) and the attitude towards technology (Table 4). 
Table 3. Relationships between students' characteristics and the usage subscales.

\begin{tabular}{|c|c|c|c|c|c|c|c|c|c|c|c|}
\hline \multicolumn{12}{|c|}{ Mean (Standard deviation) } \\
\hline Variables & E-mailing & $\begin{array}{c}\text { Text } \\
\text { messaging }\end{array}$ & $\begin{array}{l}\text { Phone } \\
\text { calling }\end{array}$ & $\begin{array}{l}\text { Smartphone } \\
\text { usage }\end{array}$ & $\begin{array}{c}\text { TV } \\
\text { viewing }\end{array}$ & $\begin{array}{c}\text { Media } \\
\text { sharing }\end{array}$ & $\begin{array}{l}\text { Internet } \\
\text { searching }\end{array}$ & $\begin{array}{l}\text { Video } \\
\text { gaming }\end{array}$ & $\begin{array}{c}\text { General } \\
\text { social } \\
\text { media } \\
\text { usage }\end{array}$ & $\begin{array}{l}\text { Facebook } \\
\text { friendships }\end{array}$ & $\begin{array}{l}\text { Online } \\
\text { friendships }\end{array}$ \\
\hline Mean (SD) & $3.6(2.0)$ & $7.5(1.9)$ & $7.4(2.0)$ & $5.8(1.6)$ & $5.0(2.1)$ & $3.1(2.0)$ & $5.7(2.4)$ & $3.5(2.6)$ & $5.5(1.9)$ & $6.1(2.2)$ & $2.3(1.5)$ \\
\hline \multicolumn{12}{|l|}{ University } \\
\hline Private & $4.9(1.9)$ & $8(1.8)$ & $7.8(1.9)$ & $6.4(1.7)$ & $5.1(2.2)$ & $3.6(2.3)$ & $6.1(2.3)$ & $4.0(2.7)$ & $5.6(1.9)$ & $6.7(2.0)$ & $2.5(1.7)$ \\
\hline Public & $3.1(1.9)^{\dagger}$ & $7.3(1.9)^{\dagger}$ & $7.2(1.9)^{\dagger}$ & $5.5(1.5)^{\dagger}$ & $5.0(2.1)$ & $2.9(1.9)^{\dagger}$ & $5.5(2.4)^{\ddagger}$ & $3.3(2.6)^{\dagger}$ & $5.4(1.8)$ & $5.9(2.2)^{\dagger}$ & $2.2(1.4)$ \\
\hline \multicolumn{12}{|l|}{ Age } \\
\hline $17-19$ & $3.2(1.9)$ & $7.6(1.9)$ & $7.4(2)$ & $5.8(1.4)$ & $5.1(2.2)$ & $2.9(2.0)$ & $5.6(2.4)$ & $3.5(2.5)$ & $5.5(1.9)$ & $6.0(2.3)$ & $2.4(1.6)$ \\
\hline $20-29$ & $3.9(2.1)$ & $7.5(1.9)$ & $7.3(1.9)$ & $5.8(1.7)$ & $5.0(2.1)$ & $3.2(2.0)$ & $5.8(2.4)$ & $3.6(2.7)$ & $5.4(1.9)$ & $6.2(2.1)$ & $2.3(1.4)$ \\
\hline$\geq 30$ & $3.3(1.4)^{\dagger}$ & $6.4(2.0)$ & $7.7(2.2)$ & $4.7(1.4)$ & $3.5(1.8)^{*}$ & $2.3(1.6)^{*}$ & $4.3(2.2)$ & $1.8(1.3)$ & $4.6(1.2)$ & $4.4(2.4)^{*}$ & $2.1(1.4)$ \\
\hline \multicolumn{12}{|l|}{ Gender } \\
\hline Male & $4.6(2.1)$ & $7.9(1.7)$ & $7.9(1.7)$ & $6.2(1.6)$ & $4.9(2.2)$ & $3.9(2.2)$ & $6.2(2.4)$ & $5.0(2.7)$ & $5.5(1.9)$ & $6.9(2.1)$ & $2.6(1.5)$ \\
\hline Female & $3.3(2.0)^{\dagger}$ & $7.4(1.9)^{\ddagger}$ & $7.2(2.0)^{\dagger}$ & $5.6(1.6)^{\dagger}$ & $5.0(2.1)$ & $2.8(1.9)^{\dagger}$ & $5.5(2.4)^{\dagger}$ & $3.0(2.4)^{\dagger}$ & $5.4(1.9)$ & $5.8(2.2)^{\dagger}$ & $2.2(1.5)^{\ddagger}$ \\
\hline \multicolumn{12}{|l|}{$\begin{array}{l}\text { Living with } \\
\text { parents }\end{array}$} \\
\hline Yes & $3.6(2.1)$ & $7.5(1.87)$ & $7.3(2.0)$ & $5.7(1.6)$ & $5.0(2.0)$ & $3.0(2.0)$ & $5.6(2.4)$ & $3.4(2.6)$ & $5.4(1.9)$ & $6.0(2.2)$ & $2.3(1.5)$ \\
\hline No & $4.3(1.9)^{\ddagger}$ & $7.9(1.7)$ & $7.7(1.7)$ & $6.1(1.6)^{*}$ & $3.9(2.1)$ & $3.9(2.1)^{\dagger}$ & $6.3(2.3)^{*}$ & $4.0(3.0)$ & $5.5(1.8)$ & $6.8(2.0)^{\ddagger}$ & $2.3(1.6)$ \\
\hline \multicolumn{12}{|l|}{ Working } \\
\hline Yes & $3.9(2.3)$ & $7.6(1.9)$ & $7.6(1.9)$ & $5.8(1.7)$ & $4.9(2.0)$ & $3.4(2.2)$ & $5.6(2.3)$ & $3.4(2.6)$ & $5.4(1.8)$ & $6.4(2.2)$ & $2.4(1.5)$ \\
\hline No & $3.5(2.0)^{*}$ & $7.5(1.8)$ & $7.3(2.0)$ & $5.7(1.6)$ & $5.1(2.2)$ & $3.0(2.0)^{\ddagger}$ & $5.7(2.4)$ & $3.5(2.7)$ & $5.5(1.9)$ & $6.0(2.2)^{*}$ & $2.3(1.5)$ \\
\hline \multicolumn{12}{|l|}{$\mathrm{GPA}^{\mathrm{a}}$} \\
\hline$<1.99$ & $4.0(2.0)$ & $7.8(2.3)$ & $7.5(2.1)$ & $5.5(1.6)$ & $4.6(1.6)$ & $3.7(2.2)$ & $5.1(1.6)$ & $3.8(2.0)$ & $5.1(1.5)$ & $6.4(2.2)$ & $2.6(1.8)$ \\
\hline $2-2.99$ & $3.3(2.1)$ & $7.5(1.9)$ & $7.3(2.0)$ & $5.6(1.7)$ & $4.8(2.1)$ & $2.9(1.9)$ & $5.6(2.4)$ & $3.4(2.6)$ & $5.5(1.9)$ & $6.1(2.2)$ & $2.3(1.4)$ \\
\hline$\geq 3$ & $4.0(2.0)^{\dagger}$ & $7.7(1.8)$ & $7.6(1.8)$ & $6.0(1.6)^{\dagger}$ & $5.2(2.2)^{*}$ & $3.3(2.2)^{*}$ & $6.0(2.4)^{*}$ & $3.6(2.7)$ & $5.6(1.9)$ & $6.3(2.1)$ & $2.4(1.6)$ \\
\hline \multicolumn{12}{|l|}{ Alcohol } \\
\hline Yes & $4.6(2.0)$ & $8.0(1.9)$ & $7.8(2.0)$ & $6.5(1.7)$ & $5.1(2.2)$ & $4.2(2.3)$ & $6.4(2.2)$ & $5.2(2.9)$ & $5.8(2.0)$ & $7.1(1.8)$ & $2.5(1.5)$ \\
\hline No & $3.5(2.0)^{\dagger}$ & $7.4(1.8)^{\ddagger}$ & $7.3(1.9)^{\ddagger}$ & $5.6(1.6)^{\dagger}$ & $5.0(2.1)$ & $2.9(1.9)^{\dagger}$ & $5.6(2.4)^{\dagger}$ & $3.2(2.5)^{\dagger}$ & $5.4(1.8)^{*}$ & $5.9(2.2)^{\dagger}$ & $2.3(1.5)$ \\
\hline \multicolumn{12}{|l|}{ Smoking } \\
\hline Yes & $4.1(2.1)$ & $7.8(1.9)$ & $7.7(1.9)$ & $6.1(1.7)$ & $5.2(2.3)$ & $3.7(2.1)$ & $6.2(2.1)$ & $4.1(2.7)$ & $5.8(2.0)$ & $6.6(2.1)$ & $2.3(1.4)$ \\
\hline No & $3.5(2.1)^{\ddagger}$ & $7.4(1.8)^{*}$ & $7.2(1.9)^{\dagger}$ & $5.6(1.6)^{\dagger}$ & $5.0(2.1)$ & $2.9(2.0)^{\dagger}$ & $5.56(2.0)^{\ddagger}$ & $3.3(2.6)^{\dagger}$ & $5.4(1.8)^{*}$ & $6.0(2.2)^{\dagger}$ & $2.3(1.5)$ \\
\hline \multicolumn{12}{|l|}{$\begin{array}{l}\text { Physical } \\
\text { activity }\end{array}$} \\
\hline Yes & $3.8(2.1)$ & $7.5(1.8)$ & $7.4(1.9)$ & $5.8(1.6)$ & $5.1(2.1)$ & $3.2(2.0)$ & $5.7(2.9)$ & $3.7(2.8)$ & $5.5(1.8)$ & $6.4(2.1)$ & $2.4(1.5)$ \\
\hline No & $3.3(2.0)^{\ddagger}$ & $7.5(1.9)$ & $7.2(2.0)$ & $5.6(1.6)^{*}$ & $4.8(2.2)$ & $2.9(2.1)$ & $5.6(2.4)$ & $3.1(2.3)^{\ddagger}$ & $5.4(1.9)$ & $5.7(2.2)^{\dagger}$ & $2.2(1.4)$ \\
\hline \multicolumn{12}{|l|}{ Insomnia } \\
\hline Yes & $3.3(1.9)$ & $7.6(2.0)$ & $7.4(2.1)$ & $5.9(1.6)$ & $4.8(2.2)$ & $3.1(2.0)$ & $6.0(2.4)$ & $3.4(2.8)$ & $5.6(1.9)$ & $6.1(2.1)$ & $2.3(1.5)$ \\
\hline No & $3.8(2.1)^{\ddagger}$ & $7.5(1.8)$ & $7.3(1.9)$ & $5.7(1.6)$ & $5.1(2.1)$ & $3.1(2.0)$ & $5.6(2.4)^{*}$ & $3.5(2.6)$ & $5.4(1.9)$ & $6.1(2.2)$ & $2.3(1.5)$ \\
\hline
\end{tabular}




\section{Continued}

\begin{tabular}{cccccccccccc}
\hline Back ache & & & & & & & & & & & \\
Yes & $3.6(1.9)$ & $7.6(1.9)$ & $7.3(2.0)$ & $5.8(1.6)$ & $4.9(2.1)$ & $3.4(2.1)$ & $5.9(2.4)$ & $3.6(2.6)$ & $5.5(1.9)$ & $6.2(2.1)$ & $2.3(1.4)$ \\
No & $3.6(2.2)$ & $7.5(1.8)$ & $7.4(1.9)$ & $5.7(1.6)$ & $5.1(2.2)$ & $3.0(2.0)^{\ddagger}$ & $5.6(2.4)^{*}$ & $3.4(2.6)$ & $5.4(1.9)$ & $6.0(2.2)$ & $2.3(1.6)$ \\
Neck ache & & & & & & & & & & & \\
Yes & $3.8(2.1)$ & $7.6(1.9)$ & $7.2(1.9)$ & $5.9(1.5)$ & $5.02 .0)$ & $3.4(2.0)$ & $5.8(2.2)$ & $3.5(2.6)$ & $5.6(1.9)$ & $6.1(2.2)$ & $2.3(1.4)$ \\
No & $3.6(2.1)$ & $7.5(1.9)$ & $7.4(2.0)$ & $5.7(1.7)$ & $5.0(2.2)$ & $3.0(2.0)^{*}$ & $5.6(2.4)$ & $3.5(2.7)$ & $5.4(1.9)$ & $6.1(2.2)$ & $2.3(1.5)$ \\
Headache & & & & & & & & & & & \\
Yes & $3.6(2.1)$ & $7.7(1.9)$ & $7.5(2.0)$ & $5.8(1.6)$ & $5.1(2.1)$ & $3.4(2.1)$ & $5.9(2.4)$ & $3.5(2.6)$ & $5.7(1.9)$ & $6.1(2.2)$ & $2.3(1.5)$ \\
No & $3.6(2.1)$ & $7.4(1.8)$ & $7.2(1.9)$ & $5.6(1.7)$ & $5.0(2.1)$ & $2.8(2.0)^{\dagger}$ & $5.5(2.4)^{\ddagger}$ & $3.5(2.7)$ & $5.2(1.8)^{\ddagger}$ & $6.1(2.2)$ & $2.3(1.5)$ \\
\hline
\end{tabular}

Notes and abbreviations: ${ }^{a}$ Grade Point Average; ${ }^{\dagger} \mathrm{p} \leq 0.001 ;{ }^{\ddagger} \mathrm{p} \leq 0.01 ;{ }^{*} \mathrm{p} \leq 0.05$. Blanks in table indicate a non-significant $\mathrm{p}$-value for the scale in that test.

Table 4. Relationship between characteristics of young students and attitudes subscales.

\begin{tabular}{|c|c|c|c|c|}
\hline \multicolumn{5}{|c|}{ Mean (Standard deviation) } \\
\hline Variables & $\begin{array}{l}\text { Positive } \\
\text { attitudes }\end{array}$ & Anxiety/dependence & $\begin{array}{l}\text { Negative } \\
\text { attitudes }\end{array}$ & $\begin{array}{l}\text { Preference for } \\
\text { task switching }\end{array}$ \\
\hline Mean (SD) & $3.96(0.59)$ & $3.57(0.90)$ & $3.54(0.82)$ & $2.90(0.72)$ \\
\hline \multicolumn{5}{|l|}{ University } \\
\hline Private & $3.98(0.63)$ & $3.53(0.94)$ & $3.42(0.89)$ & $2.77(0.76)$ \\
\hline Public & $3.95(0.57)$ & $3.59(0.88)$ & $3.58(0.78)$ & $2.95(0.70)$ \\
\hline p-value & 0.46 & 0.44 & 0.02 & 0.004 \\
\hline \multicolumn{5}{|l|}{ Gender } \\
\hline Male & $4.02(0.65)$ & $3.54(0.93)$ & $3.37(0.93)$ & $2.88(0.72)$ \\
\hline Female & $3.94(0.56)$ & $3.58(0.89)$ & $3.59(0.76)$ & $2.91(0.73)$ \\
\hline p-value & 0.84 & 0.61 & 0.002 & 0.66 \\
\hline \multicolumn{5}{|l|}{ GPA } \\
\hline$<1.99$ & $3.82(0.62)$ & $3.59(0.92)$ & $3.56(0.85)$ & $2.92(0.76)$ \\
\hline $2-2.99$ & $4.00(0.57)$ & $3.61(0.85)$ & $3.51(0.80)$ & $2.88(0.73)$ \\
\hline$\geq 3$ & $3.96(0.60)$ & $3.57(0.96)$ & $3.53(0.83)$ & $2.90(0.71)$ \\
\hline p-value & 0.30 & 0.85 & 0.84 & 0.95 \\
\hline \multicolumn{5}{|l|}{ Smoking } \\
\hline Yes & $4.02(0.63)$ & $3.69(0.96)$ & $3.50(0.85)$ & $2.91(0.68)$ \\
\hline No & $3.94(0.57)$ & $3.54(0.88)$ & $3.54(0.81)$ & $2.89(0.74)$ \\
\hline p-value & 0.18 & 0.08 & 0.55 & 0.82 \\
\hline \multicolumn{5}{|c|}{ Physical activity } \\
\hline Yes & $3.97(0.58)$ & $3.59(0.87)$ & $3.52(0.82)$ & $2.92(0.73)$ \\
\hline No & $3.94(0.59)$ & $3.54(0.94)$ & $3.57(0.81)$ & $2.85(0.72)$ \\
\hline p-value & 0.44 & 0.48 & 0.45 & 0.21 \\
\hline \multicolumn{5}{|l|}{ Insomnia } \\
\hline Yes & $4.00(0.57)$ & $3.74(0.89)$ & $3.56(0.81)$ & $2.97(0.66)$ \\
\hline No & $3.94(0.59)$ & $3.51(0.90)$ & $3.53(0.82)$ & $2.87(0.74)$ \\
\hline p-value & 0.27 & 0.003 & 0.62 & 0.10 \\
\hline
\end{tabular}




\subsection{Relationship between Full-Scale MTUAS Scores and Subgroups Characteristics}

According to full-scale MTUAS scores, 39.9\% of the university students had addictions to social media and technology.

Multivariate Regression analysis showed that the degree of addiction to social media and technology in males was higher by 2.71 times in average compared to females $(\mathrm{OR}=2.71 ; 95 \% \mathrm{CI}=1.78-4.15, \mathrm{p}=0.001)$. The addiction to technology behavior was more frequent in younger people $(\mathrm{p}=0.04)$ and far less frequent in subjects practicing work compared to those who were not work (OR $=0.66$, $95 \% \mathrm{CI}=0.44-0.98, \mathrm{p}=0.04)$. Addiction to technology was associated with alcohol $(\mathrm{OR}=1.80 ; 95 \% \mathrm{CI}=1.04-3.11, \mathrm{p}=0.04)$, smoking $(\mathrm{OR}=1.76 ; 95 \% \mathrm{CI}=$ $1.10-2.82, \mathrm{p}=0.02)$, and was two times more frequent in subjects who reported headache $(\mathrm{OR}=1.65,95 \% \mathrm{CI}=1.16-2.36, \mathrm{p}=0.01)($ Table 5$)$.

\section{Discussion}

Our study proved that the youth university students use the Internet for many hours and are addicted to technology usage. Depending on the results of this study, the most commonly used technologies were text messaging, phone calling, Facebook friendship, smartphone usage, internet searching, and general social media usage.

The Communication was made virtually, the message sent instantly, and information and documents transferred through digital tools [1].

This study has undertaken rigorous processes to translate and culturally adapt the MTUAS to the Lebanese Arab context; the Arabic version of the scale was evaluated with good psychometric properties. Concerning feasibility, it was in general very good, no confusing items, no missing data for items and scales, and the duration of administration of the questionnaire was short (10 - 15 minutes). The internal consistency generally exceeded the recommended minimum alpha coefficient standard for group comparison of 0.70 and also was higher than the reliability of the original version [17] and Portuguese MTUAS scales [8]. Indeed, a reliability of 0.5 or above considered acceptable [19]. The 15 subscales of the MTUAS showed strong validity [17]. The presence of a relation between the dimensions of MTUAS and the socio-demographic and lifestyle and academic performance characteristics supported the Construct validity of the instrument.

The Prevalence rate of technology addiction behavior in the Lebanese university students was substantial. In studies conducted abroad, the prevalence of social media and technology addiction among university students was found to be $0.7 \%$ in Turkey [20], $44 \%$ to $52 \%$ in Russia [21], and 38.3\% in Iran [22]. However, Costa et al. [8] found that Smartphone usage was the most frequent ICT reported and, contrary to what was expected, online friendship was the least frequent that was in line with our results. However, while the smartphone can bring distant people closer together, at least virtually, it can also make close people more distant. More generally, it can negatively affect the quality of time spent with others, a key determinant of individual well-being [23]. 
Table 5. Relationship between full-scale MTUAS scores and the young students' subgroups characteristics: logistic regression results.

\begin{tabular}{|c|c|c|c|c|c|c|}
\hline \multirow[b]{2}{*}{ Variables } & \multicolumn{3}{|c|}{ Description of subgroups according to full-scale MTUAS scores } & \multicolumn{3}{|c|}{ Logistic regression results } \\
\hline & $\begin{array}{l}\text { Addiction group } \\
\text { Frequency (\%) }\end{array}$ & $\begin{array}{l}\text { Normal group } \\
\text { Frequency (\%) }\end{array}$ & $\mathrm{p}$ & $\operatorname{Exp}(\beta)$ & $\begin{array}{l}95 \% \text { CI for } \\
\operatorname{EXP}(\beta)\end{array}$ & $\mathrm{p}$ \\
\hline Constant & - & - & - & 3.13 & - & 0.22 \\
\hline Gender & & & $\leq 0.001$ & & & \\
\hline Male & $111(60.7 \%)$ & $72(39.3 \%)$ & & 2.71 & \multirow{2}{*}{$1.78-4.15$} & \multirow[t]{2}{*}{$\leq 0.001$} \\
\hline Female & $170(32.6 \%)$ & $352(67.4 \%)$ & & 1 & & \\
\hline Age (mean $\pm \mathrm{SD})$ & $20.19 \pm 1.79$ & $20.75 \pm 2.73$ & 0.04 & 0.92 & $0.84-0.99$ & 0.04 \\
\hline University & & & $\leq 0.001$ & & & \\
\hline Private & $112(54.6 \%)$ & $93(45.4 \%)$ & & 1.50 & \multirow{2}{*}{$1.01-2.24$} & \multirow[t]{2}{*}{0.05} \\
\hline Public & $169(33.8 \%)$ & $331(66.2 \%)$ & & 1 & & \\
\hline Living with parents & & & 0.05 & & & \\
\hline Yes & $244(38.6 \%)$ & $388(61.4 \%)$ & & 0.65 & \multirow{2}{*}{$0.38-1.14$} & \multirow[t]{2}{*}{0.13} \\
\hline No & $37(50.7 \%)$ & $36(49.3 \%)$ & & 1 & & \\
\hline Working & & & 0.96 & & & \\
\hline Yes & $76(39.6 \%)$ & $116(60.4 \%)$ & & 0.66 & \multirow{2}{*}{$0.44-0.98$} & \multirow[t]{2}{*}{0.04} \\
\hline No & $205(40.0 \%)$ & $308(60.0 \%)$ & & 1 & & \\
\hline $\mathrm{GPA}(\mathrm{n}=642)$ & & & 0.16 & & & \\
\hline$<1.99$ & $8(38.1 \%)$ & $13(61.9 \%)$ & & 0.34 & $0.12-0.98$ & 0.10 \\
\hline $2-2.99$ & $111(37.0 \%)$ & $189(63.0 \%)$ & & 0.80 & $0.55-1.16$ & 0.04 \\
\hline$\geq 3$ & $143(44.5 \%)$ & $178(55.5 \%)$ & & 1 & 1 & 0.24 \\
\hline Alcohol & & & $\leq 0.001$ & & & \\
\hline Yes & $67(67.7 \%)$ & $32(32.3 \%)$ & & 1.80 & $1.04-3.11$ & 000 \\
\hline No & $214(35.3 \%)$ & $392(64.7 \%)$ & & & & $0.0 x$ \\
\hline Smoking & & & $\leq 0.001$ & & & \\
\hline Yes & $82(57.7 \%)$ & $60(42.3 \%)$ & & 1.76 & $1.10-2.82$ & \\
\hline No & $199(35.3 \%)$ & $364(64.7 \%)$ & & 1 & & \\
\hline Physical activity & & & 0.05 & 0.74 & $1.07-1.52$ & \\
\hline Yes & $187(42.7 \%)$ & $251(57.3 \%)$ & & & & \\
\hline No & $94(35.2 \%)$ & $173(64.8 \%)$ & & & & 0.15 \\
\hline \multicolumn{7}{|l|}{ Neck pain } \\
\hline Yes & $115(58.1)$ & 83 (41.9) & 0.50 & 0.71 & $1.05-1.54$ & \multirow{2}{*}{0.84} \\
\hline No & 309 (60.9) & $198(39.1)$ & & & & \\
\hline Headache & & & 0.03 & & & \\
\hline Yes & $153(44.0 \%)$ & $195(56.0 \%)$ & & 1.65 & $1.16-2.36$ & \multirow{2}{*}{0.01} \\
\hline No & $128(35.9 \%)$ & $229(64.1 \%)$ & & 1 & & \\
\hline full-scale MTUAS & $281(39.9 \%)$ & $424(60.1 \%)$ & - & - & - & - \\
\hline
\end{tabular}

Notes and abbreviations: Nagelkerke R Square $=16.6 \% . \mathrm{CI}=$ confidence interval. Variables shown in this table were selected because of their association with MTUAS in the univariate analysis and of their potential public health interest regarding the current situation in Lebanon. 
The present work revealed that gender, age, lifestyle, and comorbidities were associated with the technology addiction behavior. The male users have more chance to addict technology than female. Similar findings were reported from more recent studies. Matos et al. [24], using MTUAS-PY Usage scores in a sample of Portuguese adolescent found a higher usage frequency of Facebook, e-mail, and picture and video recording by females and higher usage frequency of the video games by males. Even though digital games have positive characteristics like tension release, reviving one's imagination, and etc., they may lead to addiction when the individual spends time with them excessively [1]. In contrast to our results, Boumosleh and Jaalouk [12] found that gender, residence, work hours per week, faculty, academic performance (GPA), and lifestyle habits (smoking and alcohol drinking) did not associate with smartphone addiction score [12]. Nevertheless, our study revealed that the prevalence of addictions among females' students (32.6\%) was so far lower than in Saudi Arabia (51.4\%) [25].

Our findings resonate well with prior results from others studies that reported that males are significantly more online, do significantly more media sharing [17], and play video games more often than females [17] [24] [26] [27]. The females tend to favor conversations and prefer socializing and communication [24] [27].

Concerning the attitudes toward technology, in contrast with our study, Romanian males reported higher negative attitudes toward technology than females, and females reported higher positive attitude towards technology than males [26]. Our results were concordant with those reported by Maican \& Cocoradă [28] in Romania where the switch between tasks on new technology of the Romanians youth and was equal for both genders [26]. Costaa et al. [8] showed that males and females significantly differed in their MTUAS-PY on Attitudes towards multitasking (higher value for males). In United States, on average, $29 \%$ of American youth time is spent juggling multiple media streams simultaneously (i.e., media multitasking) [29].

The overall social media and technology addiction score was higher in private than public faculties, probably due to restricted access to social media in public university. Masthi et al. [26] using Young's Internet Addiction Test in high schools in India found a similar pattern. In United-States, Rosen et al. [17] indicated that those who had a higher median income used social media more often. In France, there are no global differences between the two universities except the family income [30]. The study findings supported a study done in Lebanon that shows that the type of residence and the work of the students do not have a substantial influence on the addiction of the students to the technology [12]. Unlike the results reported by Matar [12] in Lebanon, the alcoholic students and smokers use the technology more frequently.

A multitude of physical, psychological and behavioral problems were observed among technology users. We observed physical problems (i.e. neck pain, back pain, headache). Behavioral changes, i.e. sleep disturbance were also reported 
and were in concordance with other studies conducted in India [26], Saudi Arabia [25], and Lebanon [12]. Indeed, virtual contact and communication on social media are sometimes thought to be in isolation and only online, but these are real connections that we're making and real networks. Any interaction should still be respectful and treated as though it was a real life, in-person conversation [31]. In Saudi Arabia, the female students with moderate and severe addiction mostly used the Internet mainly for entertainment purposes while non-addicts used it mainly for information purposes [25].

Our findings were similar to that Facebook was the main platforms used that was in line with the results shown by Sigerson \& Cheng [15]. In the present study, there were significant differences in Facebook addiction relating to gender. The males had higher scores than females. In contrast, female students in Romania are more active on Facebook, as they check their personal page more often at school and/or at work, read more posts, and like posts and photos [28]. Alzougool [32] found that both male and female users have the same chance to addict Facebook. In contrast, with others studies [17] [32], we found significant difference in Facebook addiction between different ages. The older youth reported significantly lower Facebook friendships than other counterparts [32].

We found that some activities can enhance or reduce the academic performance of the students. In contrast, Yilmaz et al. [20] reported that no significant relationship was found between smartphone addiction and academic success [20]. Indeed, Maican \& Cocoradă [28] mentioned that the use of the internet and the computer had definite benefits as far as learning is concerned: lower costs, enhancement of teaching and learning, increase in the access to good quality courses. Smartphones and social networking facilitate access to information and communication, and reduce boredom and loneliness. It helped in learning, in networking with other colleagues, and in research opportunities [29]. Unlike other studies, we found that academic performance did not change for students browsing other Facebook users' profiles or searching for their friends [28]. Research indicates that multitasking with media during learning (in class or at home) can negatively affect academic outcomes for youth Americans [29], Turkish students [20], and for students in the Arts and Social Sciences in South Africa [33]. Multitasking involves rapidly switching between various ongoing activities creating continuous attention shifts and disruptions [33].

This study has several limitations. First, our study used a cross-sectional design, which does not prove a causal relationship between factors and addiction to technology. Second, since there is no gold standard measures for addiction to technology, the diagnostic accuracy properties of the MTUAS cut-off scores are yet to be verified. Facebook was the main platform mentioned to describe social media. So, in general that was not understood by students do not have a Facebook account but have other accounts like Instagram for example and answered that they do not use social media. A possible explanation for different studies' outcomes may be the fact that most of the studies come from different countries where cultural effects may be playing an important role in terms of social repre- 
sentations of the Internet itself and its misuse [24]. Finally, females were more prevalent in our sample as in higher education in Lebanon [34], in most European countries [35]. A similar pattern was observed in a sample of medical students in India [27] and in Lebanon [16] where the percentage of females was respectively $70.5 \%$ and $63.4 \%$. However, in Lebanon, the gender ratio varied by university and academic discipline. In the public university, female students constituted $65 \%$ of the total student population. Females are in the majority in education, but also in health and welfare and humanities. On the other hand males are in the majority in engineering [34].

\section{Conclusion}

In conclusion, the prevalence of technology use is challenging. We found that the technology is becoming a big problem on the university student users that has an impact on their life and affect their academic performance. The MTUAS Arabic version has been evaluated as a valid and reliable instrument. Future research should seek to objectively quantify how much time is spent on what apps when users are engaged in smartphone use using other valid instruments. This study may motivate professors, counsellors, students, and academic leaders to take appropriate measures to prevent harmful use and attitude toward media and technology and to effectively promote awareness regarding high risk of addiction among young university students.

\section{Acknowledgements}

We are grateful to the students who participated in this survey, to Mrs. F. Badran for her advice on the manuscript, and to the Directors of faculties who helped to carry out this study.

\section{Conflicts of Interest}

The authors declare no conflicts of interest regarding the publication of this paper.

\section{Authors' Contributions}

This work was conducted in collaboration between all the authors. HS designed the study, conducted the literature reviews, and performed the statistical analysis. $\mathrm{RB}, \mathrm{RK}$, and $\mathrm{DZ}$ participated in the data collection and interpretation of the data. SS, ND participated in the data analyses of the study, assisted with the writing, managed literature searches. IS participated in the data analyses, and wrote the first draft of the manuscript. All authors read and approved the final manuscript.

\section{References}

[1] Kesici, A. and Tunç, N.F. (2018) Investigating the Digital Addiction Level of the University Students According to Their Purposes for Using Digital Tools. Universal 
Journal of Educational Research, 6, 235-241.

https://doi.org/10.13189/ujer.2018.060204

[2] Hudson, M. (2018) What-Is-Social-Media.

https://www.thebalancesmb.com/what-is-social-media-2890301

[3] Sahin, C. (2018) Social Media Addiction Scale-Student Form: The Reliability and Validity Study. The Turkish Online Journal of Educational Technology, 17, 169-182. http://www.tojet.net/articles/v17i1/17117.pdf

[4] Simsek, E. (2014) The Role of Internet Addiction and Social Media Membership on University Students' Psychological Capital. Contemporary Educational Technology, 5, 239-256. https://files.eric.ed.gov/fulltext/EJ1105507.pdf

[5] Zahid, A. (2016) Impact of Social Media of Student's Academic Performance. International Journal of Business and Management Invention, 5, 22-29.

https://www.ijbmi.org

[6] Mahamat, H.A. (2014) The Influence of Social Networking Sites on Students' Academic Performance in Malaysia. International Journal of Electronic Commerce Studies, 5, 247-254. https://doi.org/10.7903/ijecs.1114

[7] Gok, T. (2016) The Effects of Social Networking Sites on Students' Studying and Habits. International Journal of Research in Education and Science, 2, 85-91. https://www.ijres.net

[8] Costa, J.J., Matos, A.P., Pinheiroab, M.D., Salvadorab, M.D., Vale-Diasa, M.D. and Zenha-Relac, M. (2016) Evaluating Use and Attitudes towards Social Media and ICT for Portuguese Youth: The MTUAS-PY Scale. The European Proceedings of Social \& Behavioral Sciences, 1-17. https://doi.org/10.15405/epsbs.2016.07.02.9

[9] Echeburúa, E. (2010) Addiction to New Technologies and to Online Social Networking in Young People: A New Challenge (Abstract). Adicciones, 22, 91-95. https://www.ncbi.nlm.nih.gov/pubmed/20549142 https://doi.org/10.20882/adicciones.196

[10] Gerhart, N. (2017) Technology Addiction: How Social Network Sites Impact Our Lives. Informing Science: The International Journal of an Emerging Transdiscipline, 20, 179-194. https://www.informingscience.org/Publica https://doi.org/10.28945/3851

[11] Dukea, É. and Montag, C. (2017) Smartphone Addiction, Daily Interruptions and Self-Reported Productivity. Addictive Behaviors Reports, 6, 90-95. https://doi.org/10.1016/j.abrep.2017.07.002

[12] Boumosleh, J.M. and Jaalouk, D. (2017) Depression, Anxiety, and Smartphone Addiction in University Students-A Cross Sectional Study. PLOS ONE, 12, e0182239. https://doi.org/10.1371/journal.pone.0182239

[13] Emre, S.C. (2012) A New Addiction for Teacher Candidates: Social Networks. The Turkish Online Journal of Educational Technology, 11, 14-19.

[14] Özgür, H. (2016) Adapting the Media and Technology Usage and Attitudes Scale to Turkish. Educational Sciences. Theory \& Practice, 16, 1711-1735. https://doi.org/10.12738/estp.2016.5.0085

[15] Sigerson, L. and Cheng, C. (2018) Scales for Measuring User Engagement with Social Network Sites: A Systematic Review of Psychometric Properties. Computers in Human Behavior, 83, 87-105. https://doi.org/10.1016/j.chb.2018.01.023

[16] Samaha, A.A., Fawaz, M., Yahfoufi, N.E., Gebbawi, M., Abdallah, H., Baydoun, S.A., Ghaddar, A. and Eid, A.H. (2018) Assessing the Psychometric Properties of the Internet Addiction Test (IAT) among Lebanese College Students. Frontiers in Public Health, 6, 365. https://doi.org/10.3389/fpubh.2018.00365 
[17] Rosen, L., Whaling, K., Carrier, L., Cheever, N. and Rokkum, J. (2013) The Media and Technology Usage and Attitudes Scale: An Empirical Investigation. Computers in Human Behavior, 29, 2501-2511. https://doi.org/10.1016/j.chb.2013.06.006

[18] Nunnally, J.C. and Bernstein, I.H. (1994) Psychometric Theory. 3rd Edition, McGraw-Hill, New York, 752.

[19] Sabbah, I., Sabbah, H., Khamis, R., Sabbah, S. and Droubi, N. (2013) Health Related Quality of Life of University Students in Lebanon: Lifestyles Behaviors and Socio-Demographic Predictors. Health, 5, 1-12. https://doi.org/10.4236/health.2013.57A4001

[20] Sert, H., Yilmaz, F.T., Kumsar, A.K. and Aygin, D. (2019) Effect of Technology Addiction on Academic Success and Fatigue among Turkish University Students. Fatigue: Biomedicine, Health \& Behavior, 7, 41-51. https://doi.org/10.1080/21641846.2019.1585598

[21] Neverkovich, S.D., Bubnova, I.S., Kosarenko, N.N., Sakhieva, R.G., Sizova, Z.M., Zakharova, V.L., et al. (2018) Students' Internet Addiction: Study and Prevention. EURASIA Journal of Mathematics, Science and Technology Education, 14, 1483-1495. https://doi.org/10.29333/ejmste/83723

[22] Hamissi, J., Babaie, M., Hosseini, M. and Babaie, F. (2013) The Relationship between Emotional Intelligence and Technology Addiction among University Students. International Journal of Collaborative Research on Internal Medicine \& Public Health, 5, 310-319.

[23] Rotondi, V., Stanca, L. and Tomasuolo, M. (2017) Connecting alone: Smartphone Use, Quality of Social Interactions and Well-Being. Journal of Economic Psycholo$g y$, 63, 17-26. https://doi.org/10.1016/j.joep.2017.09.001

[24] Matos, A.P., Costa, J.J., Pinheiro, M.D., Salvador, M.D., Vale-Dia, M.D. and Zenha-Rela., M. (2016) Anxiety and Dependence to Media and Technology Use: Media Technology Use and Attitudes, and Personality Variables in Portuguese Adolescents. GAI International, 1-18. https://core.ac.uk/download/pdf/151539138.pdf

[25] Doaa, M., Abdel-Salam, D.M., Alrowaili, H.I., Albedaiwi, H.K., Alessa, A.I. and Alfayyadh, H.A. (2019) Prevalence of Internet Addiction and Its Associated Factors among Female Students at Jouf University, Saudi Arabia. Journal of the Egyptian Public Health Association, 94, 12.

[26] Masthi, N.R., Pruthvi, S. and Phaneendra, M. (2017) A Comparative Study on Social Media Addiction between Public and Private High School Students of Urban Bengaluru, India. ASEAN Journal of Psychiatry, 18, 206-215.

[27] Jain, P., Gedam, S.R. and Patil, P.S. (2019) Study of Smartphone Addiction: Prevalence, Pattern of Use, and Personality Dimensions among Medical Students from Rural Region of Central India. Open Journal of Psychiatry \& Allied Sciences, 10, 132-138.

[28] Maican, C.I. and Cocoradă, E. (2017) Computers, Internet and Smartphone Attitudes among Romanian University Students. European Journal of Multidisciplinary Studies, 2, 85-92. https://doi.org/10.26417/ejms.v5i1.p85-92

[29] Uncapher, M.R., Lin, L., Rosen, L.D., Kirkorian, H.L., Baron, N.S., Bailey, K., Wagner, A.D., et al. (2017) Media Multitasking and Cognitive, Psychological, Neural, and Learning Differences. Pediatrics, 140, S62-S66. https://doi.org/10.1542/peds.2016-1758D

[30] Janin, L. (2013) Universités publiques et universités privées: Quelles différences? https://www.digischool.fr/vie-etudiante/enseignement/universites-publique-vs-univ ersite-privees-15044.html 
[31] Rubin, R. (2019) Getting Social: Physicians Can Counteract Misinformation. The Journal of the American Medical Association, E1-E3. https://jamanetwork.com/on07/31/2019

[32] Alzougool, B. (2018) Facebook Addiction among Ordinary Users in Jordan. Proceedings of the 5 th European Conference on Social Media ECSM, Limerick Institute of Technology, Ireland. http://download.nos.org/coa631/ch3.pdf

[33] Roux, D.B. and Parry, D.A. (2017) In-Lecture Media Use and Academic Performance: Does Subject Area Matter? Computers in Human Behavior, 77, 86-94. https://doi.org/10.1016/j.chb.2017.08.030

[34] Central Administration of Statistics (2012) Education in Lebanon, Statistics in Focus (SIF). Central Administration of Statistics, Beirut, Lebanon.

[35] Franca, L.R., Dautzenberg, B., Falissard, B. and Reynaud, M. (2010) Peer Substance Use Overestimation among French University Students: A Cross-Sectional Survey. BMC Public Health, 10, 169. https://doi.org/10.1186/1471-2458-10-169 